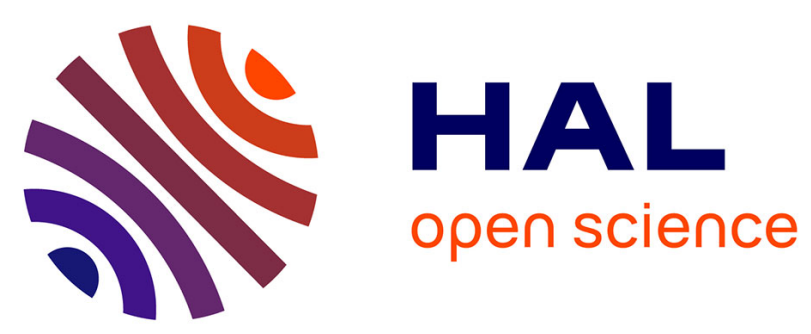

\title{
Effect of age on behavioral performance and metabolic brain activity during dual-task
}

Nounagnon Frutueux Agbangla, Michel Audiffren, Jean Pylouster, Cédric T. Albinet

\section{- To cite this version:}

Nounagnon Frutueux Agbangla, Michel Audiffren, Jean Pylouster, Cédric T. Albinet. Effect of age on behavioral performance and metabolic brain activity during dual-task. Hasan Ayaz; Frédéric Dehais. Neuroergonomics - The Brain at Work and in Everyday Life, Oct 2016, Paris, France. Elsevier, pp.235-236, 2018, Neuroergonomics - The Brain at Work and in Everyday Life. hal-02904160

\section{HAL Id: hal-02904160 \\ https://hal.science/hal-02904160}

Submitted on 21 Jul 2020

HAL is a multi-disciplinary open access archive for the deposit and dissemination of scientific research documents, whether they are published or not. The documents may come from teaching and research institutions in France or abroad, or from public or private research centers.
L'archive ouverte pluridisciplinaire HAL, est destinée au dépôt et à la diffusion de documents scientifiques de niveau recherche, publiés ou non, émanant des établissements d'enseignement et de recherche français ou étrangers, des laboratoires publics ou privés. 


\section{Introduction}

It is well documented in the literature that the attentional cost of gross motor dual-task increases with advancing age [1]. Recently, it has been demonstrated that the metabolic activity of the prefrontal cortex (PFC) decreased during walking while performing a cognitive visual task in older adults [2]. But very little works have examined the attentional cost of fine motor dual-task [3] and those few studies have not explored metabolic activity of the PFC. The objective of this study was to examine age-related effects on behavioral performance and metabolic activity of the PFC in a dual-task paradigm involving fine motor control and executive-function control.

\section{Method}

Procedure: Thirty-one adults and 33 older adults (see characteristic in table 1) performed separately and then concurrently a modified Fitts task on targets of different sizes (Index of Difficulty: IDs $=3 ; 4 ; 5$ bits) and the random number generation task (RNG). Movement time (MT) and count score (CS) were the dependent variables for the modified Fitts task and the RNG task, respectively. fNIRS data: Relative changes in concentrations of oxyhemoglobin $\left[\mathrm{O}_{2} \mathrm{Hb}\right]$ and deoxyhemoglobin $[\mathrm{HHb}]$ were recorded continuously on the left and right PFCs in each condition, with near-infrared spectroscopy (Oxymon MkIII-Artinis) with an acquisition rate of $10 \mathrm{~Hz}$. The fNIRS signals were filtered with a gaussian average filter of $1 \mathrm{~s}$. To determine the level of activation, the area under the curve (AUC) [4] was calculated for $\left[\mathrm{O}_{2} \mathrm{Hb}\right]$ and $[\mathrm{HHb}]$ for each experimental condition. Statistical analysis: Repeated measures ANOVAs were conducted on behavioral and hemodynamic data to examine age-related effects.

Table 1. Characteristic of participants

\begin{tabular}{ccc}
\cline { 2 - 3 } & Young & Older \\
\hline Age (years) & $20 \pm 1.1$ & $70.7 \pm 5.1^{*}$ \\
Gender (M/F) & $14 / 17$ & $15 / 18$ \\
Education (years) & $14.7 \pm 0.7$ & $11.9 \pm 3.3^{*}$ \\
Perdue Pegboard & $44.3 \pm 6.1$ & $41.9 \pm 4.6$ \\
MMSE & - & $28.9 \pm 1.2$ \\
GDS & - & $6.3 \pm 4.3$ \\
\hline & *: significant difference between the two groups.
\end{tabular}

\section{Results}

Behavioral data

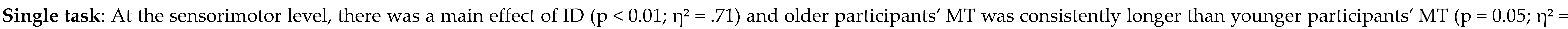
.06). At the cognitive level, older participants showed greater CS (lower cognitive performance) than the young participants ( $p<.05$ ).

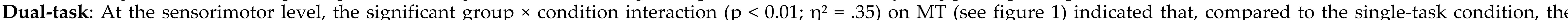

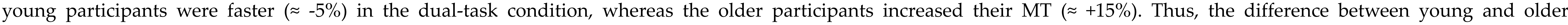
participants' MT increased in the dual-task condition $(\mathrm{p}<0.01)$.

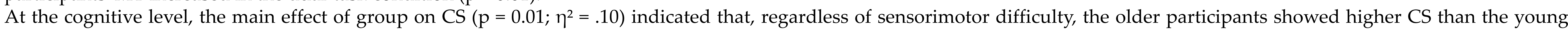
participants. The Difference in Cs comparatively to the singe-task condition was not significant in any group (see figure 2).

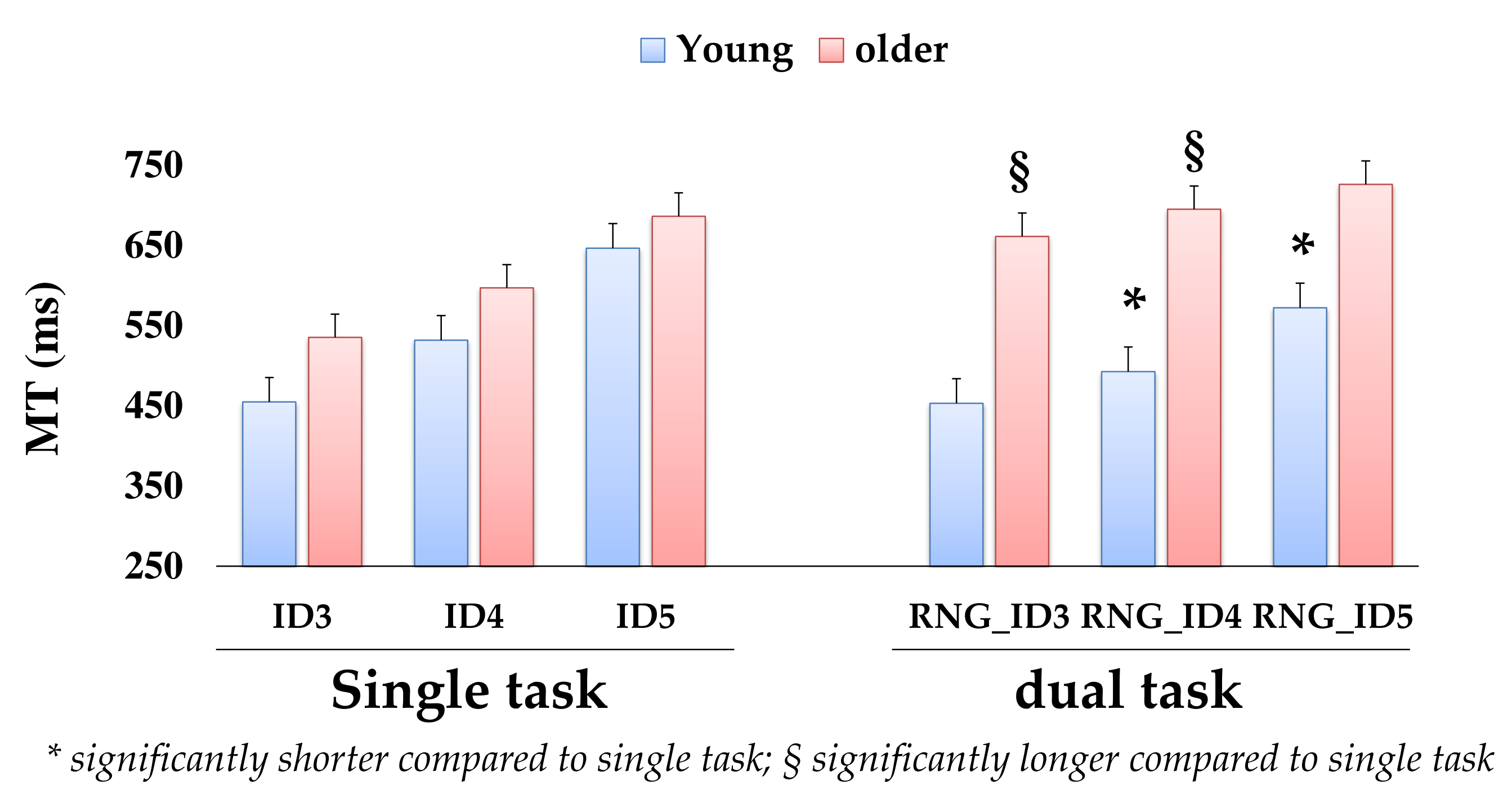

Figure 1. Evolution of MT as a function of group, ID and condition.

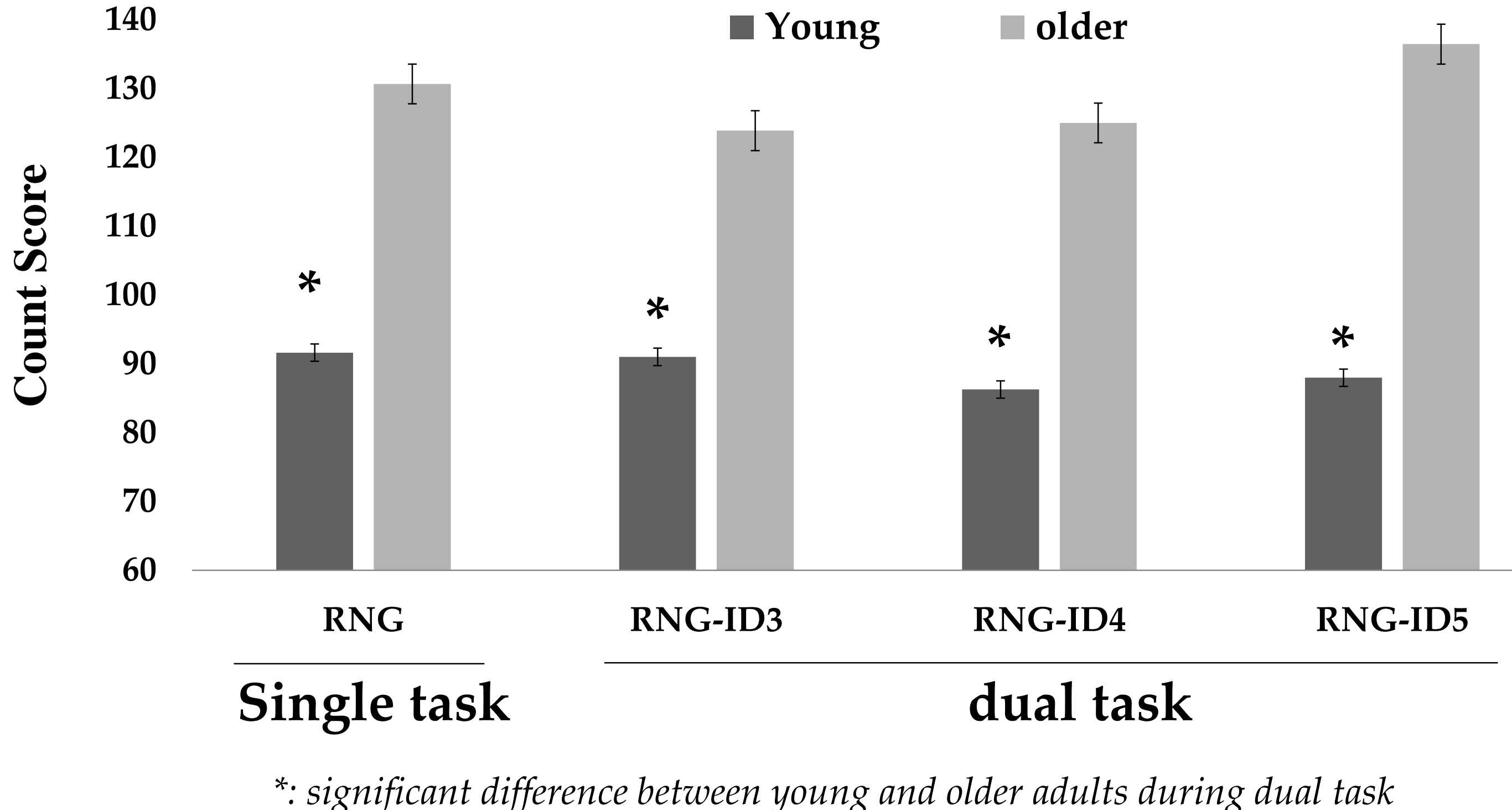

Figure 2. Evolution of CS as a function of group, ID and condition.

Hemodynamic data

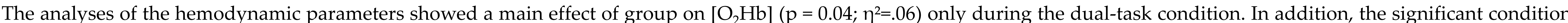

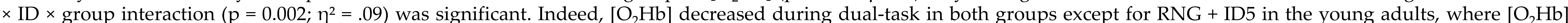
significantly increased (see figure 3 )

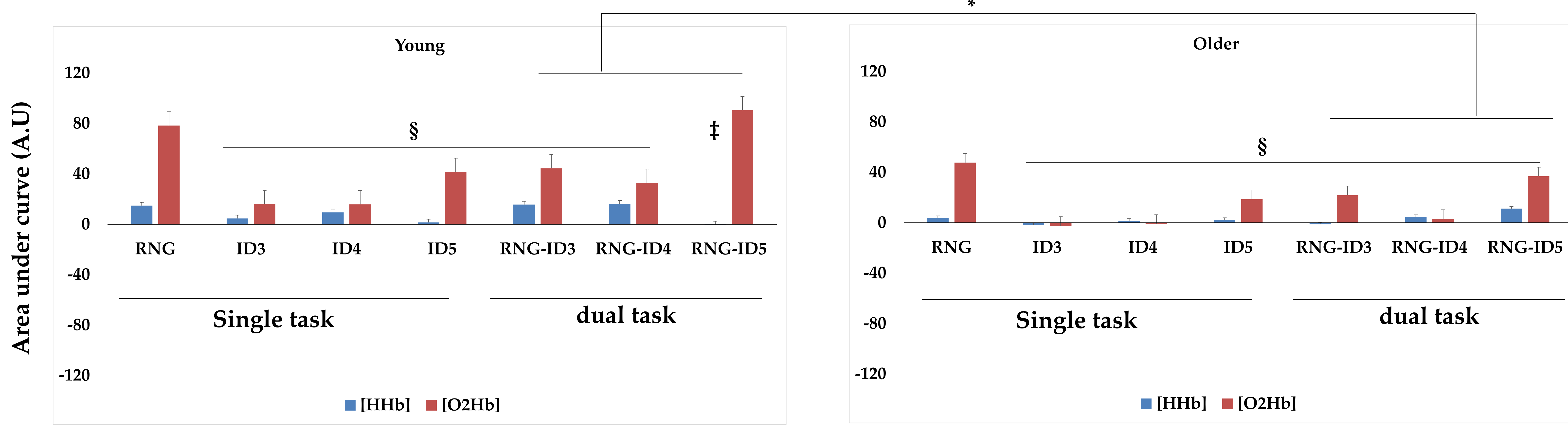

Figure 3. Evolution of the hemodynamic parameter as a function of group, ID and condition.

\section{Discussion}

This study showed large motor dual-task cost in seniors compared to young adults, but no clear dual-task cost in the cognitive domain, neither for the young nor for the older adults. These results contradict somewhat with previous results using a similar procedure [3].They may reflect that the seniors in the present study prioritized the cognitive performance, but consequently they did not have enough resources to perform the sensorimotor task correctly. At the hemodynamic level, our results showed a prominent activation of the PFC in the young adults compared to the seniors during the dual-task condition, particularly in the most difficult condition (RNG+ID5). This result partly agrees with those of Beurskens and collaborators [2], who showed that gross-motor dual-task (walking + visual checking task) was accompanied by lower PFC activity in seniors, and extend them to fine-motor dual-task. In sum, our results showed the involvement of the PFC in the management of two tasks and depicted age-related effects on this involvement.

\section{References}

[1] Lindenberger U, Marsiske M, Baltes PB. Memorizing while walking: increase in dual-task costs from young adulthood to old age. Psychol Aging. 2000; 15(3),417-436
[3] Albinet C, Tomporowski PD, Beasman K. Aging and concurrent task performance: cognitive demand and motor ontrol. Educ Gerontol. 2006: 32: 1-18.

[4] Gagnon C, Desjardins-Crépeau L, Tournier I, Desjardins M, Lesage F, Greenwood CE, \& Bherer L. Near-infrared imaging of the effects of glucose ingestion and regulation on prefrontal activation during dual-task execution in healthy 